Carbonic anhydrases in cytosol, nucleus, and membranes of rat liver.

Quistorff, Bjørn; Dodgson, Susanna J.; Ridderstråæe, Yvonne

Published in:

Journal of Applied Physiology

Publication date:

1993

Document version

Publisher's PDF, also known as Version of record

Citation for published version (APA):

Quistorff, B., Dodgson, S. J., \& Ridderstråæe, Y. (1993). Carbonic anhydrases in cytosol, nucleus, and membranes of rat liver. Journal of Applied Physiology, 75(3), 1186-1193. 


\title{
Carbonic anhydrases in cytosol, nucleus, and membranes of rat liver
}

\author{
SUSANNA J. DODGSON, BJøRN QUISTORFF, AND YVONNE RIDDERSTRÅLE \\ Department of Physiology, University of Pennsylvania School of Medicine, Philadelphia, Pennsylvania \\ 19104-6085; Nuclear Magnetic Resonance Center, Department of Biochemistry A, Panum Institute, \\ University of Copenhagen, DK-2200 Copenhagen, Denmark; and Department of Animal Physiology, \\ Swedish University of Agricultural Sciences, S-750 o7 Uppsala, Sweden
}

\begin{abstract}
Dodgson, Susanna J., BJORN QuistorfF, AND YvonNE RIDDERSTRÅLE. Carbonic anhydrases in cytosol, nucleus, and membranes of rat liver. J. Appl. Physiol. 75(3): 1186-1193, 1993. - The relative contribution of each functional carbonic anhydrase (CA) isozyme to liver CA activity of fed or starved adult male rats has been determined. The functional isozymes are CA II, CA III, CA IV, and CA V. Total CA, CA III, CA II, CA IV and $\mathrm{CA} V$ activities (in $\mu \mathrm{mol} \mathrm{CO}_{2}$ converted $\cdot \mathrm{min}^{-1} \cdot$ liver ${ }^{-1}$ ), as measured by mass spectrometric assay using $\mathrm{NaHC}^{18} \mathrm{O}^{16} \mathrm{O}$ in aqueous solution at $\mathrm{pH} 7.4$ and $37^{\circ} \mathrm{C}$, were $94,867,38,621$, $37,000,14,515$, and $<5,000$ in fed rats and $40,630,10,498,9,137$, 18,338 , and $<2,600$ in starved rats, respectively. CA II was unevenly distributed throughout the liver. In perivenous and periportal cytosols, as determined by the digitonin-pulse perfusion technique, CA II activity was (in mg cytosolic protein ${ }^{-1}$ ) 325 and 69 in fed rats and 167 and 33 in starved rats, respectively. CA III was more evenly distributed and less affected by starvation: CA III activity in perivenous and periportal cytosols was (in mg cytosolic protein ${ }^{-1}$ ) 84 and 55 in fed rats and 113 and 52 in starved rats, respectively. Evidence that CA III was concentrated in the nucleus was obtained histochemically by the Ridderstråle cobalt-precipitation technique in $2-\mu \mathrm{m}$-thick glutaraldehyde-fixed sections from adult fed rats. Liver CA activity was higher in the perivenous hepatocytes in cytosols and nuclei, whereas CA IV was homogeneously distributed. Incubation of the $2-\mu \mathrm{m}$ sections with $1 \mu \mathrm{M}$ acetazolamide resulted in inhibition of all membrane-associated CA, $50 \%$ of cytosolic CA, and no nuclear CA. We concluded that CA III comprises $50 \%$ of cytosolic CA activity and $100 \%$ of nuclear CA activity in adult male rats.
\end{abstract}

carbonic anhydrase isozymes; oxygen-18-mass spectrometric analysis; acetazolamide; cobalt precipitation; digitonin; Ridderstråle technique

THE MAJOR METABOLIC PRODUCT of the mammalian liver, $\mathrm{CO}_{2}$, reacts with $\mathrm{H}^{+} \mathrm{OH}^{-}$to form $\mathrm{HCO}_{3}^{-}$and $\mathrm{H}^{+}$; this $\mathrm{CO}_{2}$ hydration is catalyzed by the family of seven enzymes known as the carbonic anhydrases (CA; carbonate dehydratase, $\mathrm{EC} \mathrm{4.2.1.1).} \mathrm{Four} \mathrm{of} \mathrm{these} \mathrm{isozymes} \mathrm{have}$ been detected in the adult male rat liver $(6,19)$. CA II and CA III are soluble cytosolic CA isozymes; expression of these isozymes in the rat is regulated by testosterone and growth hormone, and there is almost no CA III in adult females (4). The existence of CA I, a third cytosolic isozyme, is not consensual $(19,23)$. An aim of this work was to determine whether there is functional evidence for CA $I$ in the rat liver. Other CA isozymes in the rat hepatocyte are the membrane-bound CA IV (14) and the mitochondrial CA V $(7,8)$.

A heterogeneous population of hepatocytes comprises $\sim 85 \%$ of liver cells. Some enzymes, and consequently some metabolic pathways, predominate in either the perivenous (next to the centrolobular vein) or the periportal (90\% of the liver parenchyma) region; some have a gradient of activity throughout these regions $(16,27,28)$. Only one enzyme, the soluble cytosolic glutamine synthase (15), is known to be exclusively localized to the perivenous hepatocytes; for this reason glutamine synthase was chosen as a marker enzyme for perivenous hepatocytes. The other two marker enzymes chosen were alanine amino transferase, which is known to be predominantly periportal, and pyruvate kinase, which is known to be homogeneously distributed throughout the liver (27).

It has been known for a decade that there is little CA III in neonatal male or female rats and that, as rats reach adolescence, CA III becomes the predominant cytosolic isozyme in males and CA II the predominant cytosolic isozyme in females. This sexual dimorphism has been determined to result from the different pattern of release of growth hormone in males and females $(4,19)$. CA III is also decreased, whereas $\mathrm{CA} \mathrm{V}$ is increased, in livers of streptozotocin-diabetic rats $(3,10)$.

The question of whether CA isozyme expression is changed by starvation has not previously been considered and is of importance when roles for the cytosolic CA isozymes are assigned. Starvation is known to change the activity and localization of the rate-controlling enzyme of fatty acid synthesis, acetyl CoA carboxylase $(2,11,12$, 17). It was predicted that starvation should also alter the activities and localizations of the cytosolic CA isozymes, since fatty acid synthesis results in increased hepatic $\mathrm{CO}_{2}$ production and the most likely roles of the cytosolic $\mathrm{CA}$ isozymes are to maintain intracellular $\mathrm{H}^{+}$and $\mathrm{CO}_{2}$ at concentrations enabling normal liver function.

The combination of three techniques has enabled this study. First, the dual-digitonin-pulse perfusion method enables cytosolic sampling from either the perivenous or the periportal hepatocytes (27-30). Second, the mass spectrometric ${ }^{18} \mathrm{O}$ decay technique enables measurement of $\mathrm{CA}$ activity at physiological temperature, $\mathrm{pH}$, and $\mathrm{PCO}_{2}(13,18)$. Third, the cobalt-precipitation technique (also known as the Ridderstråle technique) enables in 
situ visualization of CA activity in $2-\mu \mathrm{m}$-thick sections of fixed tissue (31).

The first aim of this study was to quantitate the activity of the cytosolic CA isozymes throughout the male rat liver. The second aim was to determine whether the cytosolic CA isozymes are functionally heterogeneously distributed throughout male rat liver. The third aim was to determine whether starvation alters the total activity and distribution of the cytosolic CA isozymes. We present evidence that 1) CA II and CA III are unevenly distributed throughout the liver, and this uneven distribution is more marked for CA II than for CA III; 2) these two cytosolic isozymes are decreased in starved rats; 3 ) there is little, if any, functional CA I activity in rat hepatocytes; 4) starved rat liver membrane-bound CA IV accounts for a higher percentage of total CA activity than either CA II or CA III; and 5) intracellular locations of CA III include the cytoplasm and the nucleus.

\section{MATERIALS AND METHODS}

Enzymes used in coupled enzyme assays were all bought from Boehringer. $\left[{ }^{18} \mathrm{O}\right] \mathrm{NaHCO}_{3}$ was prepared by incubation of the unlabeled salt with $\mathrm{H}_{2}{ }^{18} \mathrm{O}$ (18). All other chemicals were bought from Sigma Chemical (St. Louis, MO).

Male Wistar rats (170-190 g) were maintained in Copenhagen in two groups. In the $48 \mathrm{~h}$ before death, rat chow was given to the first group (fed group) but was denied to the second group (starved group). Water was freely available. Rats were maintained in a windowless room with $12 \mathrm{~h}$ of light from 9 A.M. to 9 P.M. They were killed between 10 A.M. and 12 P.M. Rats were anesthetized intraperitoneally (pentobarbital sodium, $30 \mathrm{mg} / \mathrm{kg}$ body wt) $30 \mathrm{~min}$ before surgery, and then were given $95 \%$ $\mathrm{O}_{2}-5 \% \mathrm{CO}_{2}$ to breathe $10 \mathrm{~min}$ before surgery. Livers were perfused with Krebs-Henseleit bicarbonate saline buffer $95 \% \mathrm{O}_{2}-5 \% \mathrm{CO}_{2}(22)$, excised from the rat, and weighed; a lobe was removed and homogenized; and cytosolic eluates from perivenous and periportal hepatocytes were collected by the dual-digitonin-pulse perfusion technique $(11,12,27-30)$.

Liver biopsies were homogenized in 10 volumes of icecold buffer $(25 \mathrm{mM}$ glycyl-glycine, $150 \mathrm{mM} \mathrm{KCl}, 5 \mathrm{mM}$ $\mathrm{MgSO}_{4}, 5 \mathrm{mM} \mathrm{Na} \mathrm{EDTA}_{2} 10 \mathrm{mM}$ mercaptoethanol, and $0.2 \%$ bovine serum albumin, $\mathrm{pH} 7.4$ ) in a PotterElvehjem homogenizer followed by sonication for $10 \mathrm{~s}$ at $30 \mathrm{~W}$ (Sonnifier B-12, Branson, Danbury, CT).

For assays of marker enzymes, homogenates were centrifuged for $15 \mathrm{~min}$ at $16,000 \mathrm{~g}$ at $4^{\circ} \mathrm{C}$ and the supernatants were assayed for activity of alanine amino transferase (1), pyruvate kinase (1), glutamate dehydrogenase (1), and glutamine synthase $(27,32)$ at $37^{\circ} \mathrm{C}$. Enzyme activities were calculated in terms of units, where one unit of enzyme catalyzes the formation of one micromole of product per minute. These values are given in terms of units per milligram of protein. Protein concentrations were determined by the Lowry technique (24).

Liver homogenates and liver cytosols were frozen immediately with liquid $\mathrm{N}_{2}$. Samples were either freezedried or stored at $-70^{\circ} \mathrm{C}$ before being flown on dry ice to Philadelphia, PA, for CA measurements. CA activities were the same in freeze-dried and frozen samples. Freeze-dried samples were reconstituted by adding water to the microfuge tubes.

$\mathrm{CA}$ activity was measured at $37^{\circ} \mathrm{C}$ by the ${ }^{18} \mathrm{O}$-mass spectrometric technique by continuously monitoring the rate of disappearance of dissolved ${ }^{12} \mathrm{C}^{18} \mathrm{O}^{16} \mathrm{O}$ (mass 46) and ${ }^{12} \mathrm{C}^{16} \mathrm{O}_{2}$ (mass 44) from the aqueous bicarbonate solution $\left(25 \mathrm{mM} \mathrm{NaHCO}_{3}, 1 \%\right.$ labeled with $\left.{ }^{18} \mathrm{O}\right)$ in the 3-ml reaction chamber of the mass spectrometer (Masspektrometer CH 7A, Varian Mat, Bremen, Germany). After having first ascertained that CA II and CA III were the only functional CA isozymes in cytosolic samples (see RESULTS), we used a technique that we previously developed for measuring both isozymes in a single sample (10). The decay in the ${ }^{12} \mathrm{C}^{18} \mathrm{O}^{16} \mathrm{O}$ peak at $37^{\circ} \mathrm{C}$ and $\mathrm{pH} 7.4$ and in $25 \mathrm{mM} \mathrm{NaHCO}_{3}\left(1 \%\right.$ labeled with $\left.{ }^{18} \mathrm{O}\right)$ gave the uncatalyzed rate of $\mathrm{CO}_{2}$ hydration; after cytosol was added, the accelerated decay provided both CA II and CA III activities. Activity of CA III was determined from the accelerated rate of decay of the ${ }^{12} \mathrm{C}^{18} \mathrm{O}^{16} \mathrm{O}$ peak in the presence of $7 \mu \mathrm{M}$ acetazolamide in the reaction chamber; CA II activity was determined by subtracting the calculated activity of CA III from the calculated total CA activity. CA III activity was unaltered by $<25 \mu \mathrm{M}$ acetazolamide, whereas all other CA isozymes were inhibited by $<0.5 \mu \mathrm{M}$ acetazolamide (10).

CA activity in liver fractions and in liver homogenates was calculated from the half time of the rate of decay of ${ }^{12} \mathrm{C}^{18} \mathrm{O}^{16} \mathrm{O}$ by using equations previously described in detail $(9,18)$

$$
k_{\text {enz }}=\left(k_{\text {cat }}-k_{\text {uncat }}\right) \cdot \mathrm{mg} \text { protein }^{-1} \cdot \mathrm{ml} \text { solution }
$$

where $k_{\text {enz }}$ is the velocity constant for the enzyme reaction, and $k_{\text {cat }}$ and $k_{\text {uncat }}$ are the velocity constants for catalyzed and uncatalyzed reactions, respectively.

It has previously been determined that $k_{\text {enz }}$ is related to enzyme velocity (9)

$$
k_{\text {enz }}=\text { velocity } /\left[\mathrm{CO}_{2}\right]=V_{\max } /\left\{\left[\mathrm{CO}_{2}\right]\left(1+k_{-2}\right)+K_{\mathrm{m}}\right\}
$$

where $V_{\max }$ is the reaction velocity, $k_{-2}$ is a velocity constant, $K_{\mathrm{m}}^{\max }$ is the Michaelis-Menten constant, and $\left[\mathrm{CO}_{2}\right]$ is calculated to be $1.08 \mathrm{mM}$ in a solution of $25 \mathrm{mM} \mathrm{NaHCO}_{3}$ at $\mathrm{pH} 7.4$ and $37^{\circ} \mathrm{C}$ from the Henderson-Hasselbalch equation

$$
\mathrm{pH}=\mathrm{p} K^{\prime}+\log \left(\left[\mathrm{HCO}_{3}^{-}\right] /\left[\mathrm{CO}_{2}\right]\right)
$$

(where $\mathrm{p} K^{\prime}$ is the dissociation constant) with, at $37^{\circ} \mathrm{C}$

$$
\mathrm{p} K^{\prime}=6.30-0.59 \sqrt{\omega}
$$

where $\omega$ is ionic strength (9).

CA activity (as a function of protein concentration, in $\mathrm{mg} / \mathrm{ml}$ ) in liver fractions and homogenates is also expressible in terms of enzyme units

$$
\begin{aligned}
60\left[\mathrm{CO}_{2}\right] k_{\mathrm{enz}}=(\mu \mathrm{mol} \mathrm{CO} & \text { converted to } \left.\mathrm{HCO}_{3}^{-}\right) \\
& \times \mathrm{min}^{-1} \cdot \mathrm{mg} \text { protein }
\end{aligned}
$$

Data are also given, where possible, for whole livers; these values were calculated from the weight of each whole liver and the protein concentration of that liver.

Data are presented as means \pm SE. Statistical comparisons of samples between fed and starved rats were made 


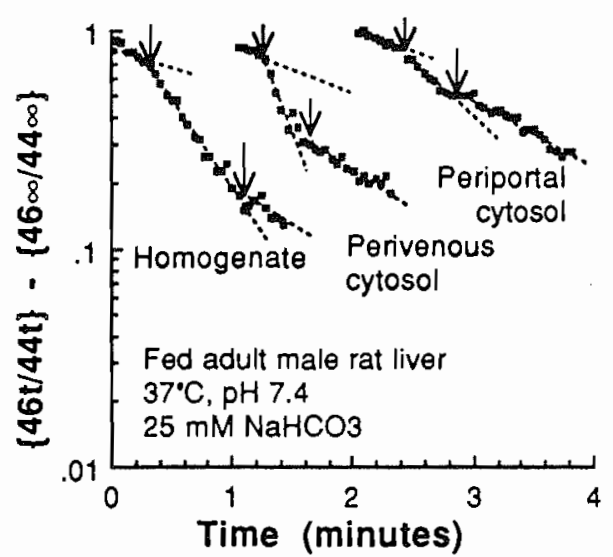

FIG. 1. Rates of disappearance of $\left\{\left[\mathrm{C}^{18} \mathrm{O}^{16} \mathrm{O}\right.\right.$ at time $t(46 \mathrm{t}) / \mathrm{C}^{16} \mathrm{O}_{2}$ at time $t(44 \mathrm{t})]-\left[\mathrm{C}^{18} \mathrm{O}^{16} \mathrm{O}\right.$ at time $\infty(46 \infty) / \mathrm{C}^{26} \mathrm{O}_{2}$ at time $\left.\left.\infty(44 \infty)\right]\right\}$ vs. time. Plots were obtained consecutively. At beginning of each experiment, $\left[{ }^{18} \mathrm{O}\right] \mathrm{NaHCO}_{3}(25 \mathrm{mM})$ was added to reaction chamber of mass spectrometer and $\mathrm{pH}$ was adjusted to 7.4. After mass 46 peak $\left(\mathrm{C}^{18} \mathrm{O}^{16} \mathrm{O}\right)$ had decayed steadily for $>10$ peaks, samples were-added to reaction chamber (1st arrows). Samples added then were freeze-thawed liver homogenates $(0.36 \mathrm{mg}$ protein $/ \mathrm{ml})$ taken before digitonin perfusion or were cytoplasmic samples taken from periportal $(0.21 \mathrm{mg}$ protein $/ \mathrm{mI})$ or perivenous $(0.16 \mathrm{mg}$ protein $/ \mathrm{ml})$ hepatocytes. Each sample in this experiment came from 1 rat liver. Acetazolamide was added to reaction chamber (final concentration $7 \mu \mathrm{M}$ ) at times indicated by 2 nd arrows.

with Student's two-tailed $t$ test with paired samples from each rat.

Histochemical samples were obtained from normally fed adult rats (200 g, Sprague-Dawley); these rats were maintained in Philadelphia and were fed rat chow. Rats were anesthetized by intraperitoneal injection of pentobarbital sodium ( $30 \mathrm{mg} / \mathrm{kg}$ body wt). The livers were first perfused with physiological saline until they were exsanguinated, perfused with fixative $(2.5 \%$ glutaraldehyde in $0.1 \mathrm{M}$ phosphate buffer), and then cut into 5 - $\mathrm{mm}$-thick slices. The pieces were left in the fixative for $4 \mathrm{~h}$, thoroughly rinsed and stored in $0.1 \mathrm{M}$ phosphate buffer at $5^{\circ} \mathrm{C}$, and then flown to Uppsala, Sweden. In Uppsala, the liver pieces were embedded in Historesin (ReichertJung) and sectioned for visualization of CA activity throughout the liver by the Ridderstråle technique (31). In this technique, $2-\mu \mathrm{m}$ sections are floated on top of a $\mathrm{CoSO}_{4}-\mathrm{H}_{2} \mathrm{SO}_{4}-\mathrm{KH}_{2} \mathrm{PO}_{4}-\mathrm{NaHCO}_{3}$ solution before they are added to $\mathrm{a}\left(\mathrm{NH}_{4}\right)_{2} \mathrm{~S}$ solution for converting the cobalt complex to CoS that is deposited at sites of CA activity.

\section{RESULTS}

Figure 1 represents a series of three consecutive CA assays of samples removed from the perfused liver of a normally fed adult rat. The assays were from the homogenized liver, prepared from the lobe biopsied before cytosolic elution, and the cytosolic samples subsequently eluted consecutively from the periportal and the perivenous hepatocytes. In each sample, CA activity was reduced by including $7 \mu \mathrm{M}$ acetazolamide, which demonstrated the presence of acetazolamide-sensitive isozymes as well as the acetazolamide-insensitive CA isozyme CA III. Each sample set in this report was assayed in this manner for CA activity.

Activities of several liver enzymes in homogenates from fed and starved rat livers are given in Table 1. Each marker enzyme was soluble; all but the mitochondrially located glutamate dehydrogenase were cytosolic. Alanine amino transferase and glutamate dehydrogenase were significantly increased and glutamine synthase and pyruvate kinase were significantly decreased in starved rats. The distribution in the perivenous and periportal hepatocytes of a number of cytosolic enzymes is indicated by the data in Table 2 and confirmed previous measurements $(11,12,28)$. The exclusive location of glutamine synthase in the perivenous hepatocytes (15) is indicated by the $>100$-fold gradient observed, whereas there is a 10 -fold periportal-perivenous gradient for alanine amino transferase and no gradient for pyruvate kinase (28). Although starvation did not significantly affect the gradients of any of the marker enzymes, there were significant changes in the activities of each of these enzymes. The data in Table 2 confirm the heterogeneous distribution of glutamine synthase, which is predominantly perivenous (15). The virtual absence of activity from the cytosolic eluates of the mitochondrial marker enzyme glutamate dehydrogenase indicates, first, that intact mitochondria were not eluted and, second, that the contents of disrupted mitochondria were not eluted. Pyruvate kinase has been previously found to be distributed evenly throughout the liver by the digitonin technique (27), which has been confirmed histochemically (30).

Experiments designed to determine the number of functionally active $\mathrm{CA}$ isozymes in the cytosols revealed little, if any, active CA I in the rat liver. The first set of evidence for this conclusion was obtained by measuring the activity of samples of homogenate and perivenous and periportal cytosol from livers of either fed or starved rats. CA activity was the same whether these samples were assayed in water, $150 \mathrm{mM} \mathrm{NaCl}$, or $100 \mathrm{mM}$ $\mathrm{Na}_{2} \mathrm{SO}_{4}$. The data in Fig. 2 were compiled from experiments completed with perivenous and periportal cytosolic samples from the liver of a single starved rat. Because a well-known characteristic of CA I is its inhibition by millimolar concentrations of chloride $(9,20)$, these data lead to the conclusion that either rat $C A$ I is insusceptible to chloride or there is little CA I in the rat liver. The next series of experiments did not eliminate the possibility that rat CA I is unaffected by halides but did indicate that there is little functional CA I in adult male rat liver; the only cytosolic $\mathrm{CA}$ isozyme that bromopyruvate functionally inactivates is CA I during a 20 -min incubation with this substance. Homogenates were centrifuged at $13,000 \mathrm{~g}$, and the supernatants were incubated in either $75 \mathrm{mM}$ bis(2-hydroxyethyl)imino-tris(hydroxymethyl)amino ethane (Bis-Tris) sulfate ( $\mathrm{pH} 7.2$; control) or $15 \mathrm{mM}$ bromopyruvate and $75 \mathrm{mM}$ Bis-Tris sulfate ( $\mathrm{pH} 7.2$ ) for $20 \mathrm{~min}$ at room temperature (20). CA activity of the supernatants was unaltered by bromopyruvate incubation. To test whether rat CA I is ever inhibited by incubation with bromopyruvate, freeze-thawed blood from an adult 200-g rat (known to contain both CA I and CA II) was incubated for $20 \mathrm{~min}$ in the presence and absence of bromopyruvate. These data showed a $20 \%$ decrease in activity in the samples in which bromopyruvate was included, which demonstrated sensitivity of rat CA I to bromopyruvate incubation.

The relative contribution of each liver $\mathrm{CA}$ isozyme to 
TABLE 1. Specific activities of marker enzymes in rat liver homogenate samples

\begin{tabular}{lccccc}
\hline & & & & Starved Rats \\
\cline { 2 - 5 } Enzyme & U/mg protein & U/liver & & U/mg protein & U/liver \\
\hline Glutamine synthase & $0.031 \pm 0.01$ & $39 \pm 1$ & & $0.021 \pm 0.002$ & $21 \pm 2$ \\
Alanine amino transferase & $0.101 \pm 0.008$ & $126 \pm 10$ & & $0.170 \pm 0.008$ & $172 \pm 8$ \\
Pyruvate kinase & $0.498 \pm 0.049$ & $621 \pm 61$ & & $0.200 \pm 0.017$ & $202 \pm 17$ \\
Glutamate dehydrogenase & $0.989 \pm 0.069$ & $1,233 \pm 86$ & & $1.610 \pm 0.008$ & $1,630 \pm 8$ \\
\hline
\end{tabular}

Values are means $\pm \mathrm{SE} ; n=4$ starved and 4 fed rats. After abdomen of anesthetized rat was opened, lower right lateral lobe of liver was removed before digitonin-pulse procedure eluted cytosolic samples from periportal and perivenous hepatocytes. Lobe was then rapidly frozen, pulverized, thawed, and centrifuged, and supernatant fractions were used for enzyme assay. By paired $t$ test, cytosolic pyruvate kinase and cytosolic glutamine synthase were significantly decreased in starved rats $(P<0.05)$, whereas mitochondrial glutamate dehydrogenase and cytosolic alanine amino transferase were significantly increased in starved rats $(P<0.05)$.

total liver CA activity is presented in Table 3 . CA activities of liver homogenates and the supernatant from freeze-thawed homogenate samples centrifuged at $100,000 \mathrm{~g}$ were measured in the presence and absence of 7 $\mu \mathrm{M}$ acetazolamide. Our first observation was that CA II and CA III provided equivalent amounts to the total homogenate CA activity. Our most surprising observation was that CA IV provided $15 \%$ of the total activity in fed rat livers and as much as $45 \%$ of the total activity in starved rat livers; CA IV provides a higher percentage of total CA activity than was previously believed $(10,14$, 19). These data indicate that starvation decreases total CA activity with no effect on membrane-bound CA IV.

The question of functional localization of the soluble isozymes CA II and CA III is addressed by the data of Table 4. Our first observation was that there was approximately the same amount of activity of CA II as there was of CA III in periportal cytosols from fed rats, as was also seen in the homogenized liver samples. This was not observed in perivenous cytosols, where there was considerably less CA III than CA II. In starved rats, CA III activity was not significantly altered in either the perivenous or the periportal cytosols; this finding contrasts with the halving of the amount of CA II in both cytosols and also contrasts with the significant decrease in CA III in homogenized liver (Table 3 ). The discrepancies in CA III activity suggest that there may be an additional intracellular location for CA III.

Possible other intracellular compartments for CA III were investigated by histochemical studies (Figs. 3 and 4). The mitochondria are ruled out as a candidate compartment, since all soluble mitochondrial CA can be inhibited by micromolar concentrations of acetazolamide (8). Figure 3 is a 300 -fold magnification of a $2-\mu \mathrm{m}$-thick section of a fed rat liver incubated for $6 \mathrm{~min}$ with reagents for the cobalt-precipitation technique. CA activity is clearly visible in the bile ducts, on the hepatocyte membranes as well as in the nuclei in the perivenous hepatocytes. The cytosolic staining in the hepatocytes is darker in some, but not all, of the perivenous hepatocytes. This photograph also indicates that CA activity is more abundant in the perivenous hepatocytes, which is in agreement with the data in Table 4, and that the mem. brane-bound CA IV is distributed homogeneously. This picture also indicates that the transition between the cytosolic CA activity of perivenous and periportal hepatocytes is abrupt, although some cells near the perivenous cells have intermediate staining between the perivenous and periportal hepatocytes.

Figure 4 is a 300 -fold magnification of the same liver in which a $2-\mu \mathrm{m}$-thick section of a fed rat liver was incubated additionally with $1 \mu \mathrm{M}$ acetazolamide. At this concentration, all CA isozymes but CA III are completely inhibited. CA activity is visible in the nuclei but is completely gone from the membranes, and there is less in the cytosols. These data are consistent with sequestration of CA III in the nuclei.

Figures 3 and 4 also provide information about the intracellular location of CA II. Liver sections from five rats indicated that the basic staining pattern was the same in each: intense perivenous staining, weak or absent periportal cytoplasmic staining, and intense mem. brane staining. The virtual absence of periportal cytoplasmic staining indicates that the cytoplasmic CA activity is located close to the plasma membrane in these hepatocytes.

The histochemical pictures together with the biochemical data demonstrate for the first time that the CA isozymes are heterogeneously distributed throughout the cell as well as throughout the liver. They further point to a specific function of CA II in the perivenous hepatocytes.

TABLE 2. Specific activities of marker enzymes in periportal and perivenous hepatocyte samples

\begin{tabular}{clcccc}
\hline Location & Condition & $\begin{array}{c}\text { Glutamine } \\
\text { Synthase }\end{array}$ & $\begin{array}{c}\text { Alanine Amino } \\
\text { Transferase }\end{array}$ & $\begin{array}{c}\text { Pyruvate } \\
\text { Kinase }\end{array}$ & $\begin{array}{c}\text { Glutamate } \\
\text { Dehydrogenase }\end{array}$ \\
\hline Periportal & Fed & $0.004 \pm 0.003$ & $0.426 \pm 0.062$ & $0.979 \pm 0.069$ & $0.004 \pm 0.002$ \\
& Starved & $0.005 \pm 0.002$ & $0.596 \pm 0.085$ & $0.495 \pm 0.039$ & $0.004 \pm 0.003$ \\
Perivenous & Fed & $0.646 \pm 0.045$ & $0.044 \pm 0.002$ & $1.011 \pm 0.031$ & $0.003 \pm 0.001$ \\
Main location & Starved & $0.443 \pm 0.027$ & $0.116 \pm 0.035$ & $0.572 \pm 0.031$ & $0.002 \pm 0.001$ \\
& & PV & PP & PV, PP & \\
\hline
\end{tabular}

Values are means $\pm \mathrm{SE}$ in U/mg cytosolic protein. Measurements were made with cytosolic fractions obtained from same 4 fed and 4 starved rats from which homogenate liver fractions were assayed (Table 1). PV, perivenous; PP, periportal. 


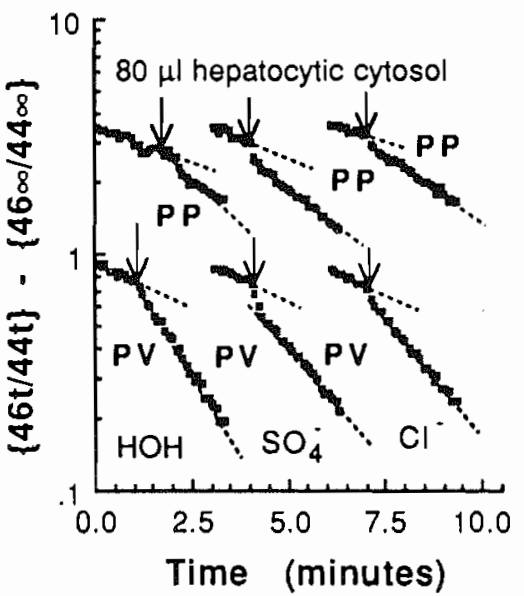

FIC. 2. Rates of disappearance of $\left\{\left[\mathrm{C}^{18} \mathrm{O}^{16} \mathrm{O}\right.\right.$ at time $t(46 \mathrm{t}) / \mathrm{C}^{16} \mathrm{O}_{2}$ at time $t(44 \mathrm{t})]-\left[\mathrm{C}^{18} \mathrm{O}^{16} \mathrm{O}\right.$ at time $\infty(46 \infty) / \mathrm{C}^{16} \mathrm{O}_{2}$ at time $\left.\left.\infty(44 \infty)\right]\right\}$ vs. time. Plots were obtained consecutively. At beginning of each experiment, $\left[{ }^{18} \mathrm{O}_{\mathrm{NaHCO}}(25 \mathrm{mM})\right.$ in $\mathrm{HOH}, 100 \mathrm{mM} \mathrm{Na}_{2} \mathrm{SO}_{4}$, or $150 \mathrm{mM}$ $\mathrm{NaCl}$ was added to reaction chamber of mass spectrometer and $\mathrm{pH}$ was adjusted to 7.4 (arrows). Samples added were freeze-dried cytosolic samples from perivenous (PV) or periportal (PP) hepatocytes, and protein concentration in reaction chamber in each experiment was 0.1 $\mathrm{mg} / \mathrm{ml}$.

\section{DISCUSSION}

This study is the first to determine the activities of the individual $\mathrm{CA}$ isozymes throughout the adult rat liver; the data demonstrate that both the cytosolic CA II and CA III isozymes are distributed unevenly throughout the liver and that CA III is also in the nucleus. This study has also provided evidence that the cytosolic CA isozymes are decreased by starvation.

In homogenized liver, the cytosolic enzymes glutamine synthase and pyruvate kinase decreased in rats starved for $48 \mathrm{~h}$; this report indicates that the activities of CA II and CA III also decrease but the activities of alanine amino transferase and glutamate dehydrogenase increase. These are the first data indicating that the expressions of the soluble CA isozymes CA II and CA III can be changed by feeding; these decreases are similar to the reported decreased activities of the lipogenic enzymes acetyl $\mathrm{CoA}$ carboxylase and pyruvate carboxylase after 48 h of starvation $(2,21,33)$. The decrease in CA II in starved compared with fed rats and the greater abundance of CA II in perivenous hepatocytes than periportal hepatocytes parallel reported observations of the committing enzyme of fatty acid synthesis, acetyl CoA carboxylase: the rate of fatty acid synthesis and the activity of acetyl CoA carboxylase are markedly enhanced in perivenous compared with periportal hepatocytes (17). Activity of the citrate- and phosphate-dependent acetyl CoA carboxylase has also been reported to decrease in the livers of starved adult rats compared with fed rats $(25)$.

It has been previously demonstrated that liver CA III decreases but the mitochondrial CA V increases in steptozotocin-diabetic rats with respect to control rats (10) and that in fed rats $\mathrm{CA} \mathrm{V}$ increases in the whole liver (Cohen, Raijman, and Dodgson, unpublished results). Further indications that the liver CA isozymes are altered by stress are given by the present results; these results also indicate that the $\mathrm{CA}$ isozymes, products of different genes, are regulated independently. Mitochondrial CA V is the only hepatic CA isozyme for which a function has been established: that of providing $\mathrm{HCO}_{3}^{-}$ for carbamyl phosphate synthase I, the first enzyme in urea synthesis, and for pyruvate carboxylase (6). The observation that membrane-bound CA IV contributes to $15 \%$ of the total activity in fed rats and to $45 \%$ of the total activity in starved rats perhaps may indicate that CA IV is of greater importance in maintaining intracellular $\mathrm{pH}$ and $\mathrm{HCO}_{3}^{-}$concentration in gluconeogenic livers than in lipogenic livers.

The data in Tables 3 and 4 indicate that CA activity of freeze-thawed homogenate supernatant is not the same as CA activity of cytosolic eluates: both CA II and CA III activities decrease in liver homogenates of starved rats, and yet in the cytosolic preparations only CA II decreases. The explanation that soluble $\mathrm{CA}$ is sequestered in another organelle is supported by Fig. 3, which indicates that there is a large concentration of $\mathrm{CA}$ activity in the nuclei. Nuclei may not stain for CA when there is no cytosolic CA in the cell (Ridderstråle, unpublished results); in the liver, nuclear staining is not removed by including $1 \mu \mathrm{M}$ acetazolamide in the incubating medium, indicating that CA III is the isozyme present. From Table 3 , it is concluded that nuclear CA III decreases but cytosolic CA III remains unchanged in response to starvation. This finding is intriguing, but its significance is completely mysterious. Nuclear staining has certainly been observed before, but, in the absence of any evidence for

TABLE 3. Carbonic anhydrase isozyme activity in whole rat liver

\begin{tabular}{|c|c|c|c|c|c|}
\hline \multirow{2}{*}{$\begin{array}{c}\text { CA } \\
\text { Isozyme }\end{array}$} & \multirow{2}{*}{$\begin{array}{l}\text { Hepatocyte } \\
\text { Compartment }\end{array}$} & \multicolumn{2}{|c|}{ Fed Rats } & \multicolumn{2}{|c|}{ Starved Rats } \\
\hline & & mg protein ${ }^{-1}$ & liver $^{-1}$ & mg protein ${ }^{-1}$ & liver $^{-1}$ \\
\hline All CAs & Homogenized liver & $77 \pm 14$ & $94,867 \pm 17,679$ & $40 \pm 4^{*}$ & $40,630 \pm 3,888$ \\
\hline CA III & Supernatant & $31 \pm 9$ & $38,621 \pm 11,275$ & $10 \pm 2^{*}$ & $10,498 \pm 2,138$ \\
\hline CA II & Supernatant & $30 \pm 1$ & $37,001 \pm 1,620$ & $9 \pm 2^{*}$ & $9,137 \pm 1,814$ \\
\hline CA IV & Membrane & $12 \pm 4$ & $14,515 \pm 4,795$ & $19 \pm 2$ & $18,995 \pm 2,148$ \\
\hline CA V & Mitochondria & $<4$ & $<5,000$ & $<2$ & $<2,000$ \\
\hline
\end{tabular}

Values are means $\pm \mathrm{SE}$ in $\mu \mathrm{mol} \mathrm{CO}$ converted to $\mathrm{HCO}_{3}^{-} / \mathrm{min}$. After it was determined that CA II and CA III were sole isozymes present in homogenate supernatant, activity of these isozymes was measured directly; from these data CA II and CA IV were calculated in whole liver homogenates. CA V provides $<5 \%$ of total carbonic anhydrase activity (10); values given in last line were calculated with this assumption and from previously published data (10). Activities were measured in $25 \mathrm{mM}$ bicarbonate at $\mathrm{pH}$ 7.4. At this pH, concentration of $\mathrm{CO}_{2}$ is $1 \mathrm{mM}$, which is less than Michaelis-Menten constants for most isozymes considered. Enzyme activities given are thus not at maximum reaction velocities and are physiological activities, and thus ratios of enzyme activities will not be same as if they were all measured at maximal reaction velocities. 
TABLE 4. Carbonic anhydrase activities in cytosols from perivenous and periportal hepatocytes

\begin{tabular}{lcccccc}
\hline \hline & \multicolumn{2}{c}{ Fed Rats } & & \multicolumn{2}{c}{ Starved Rats } \\
\cline { 2 - 3 } & CA III & CA II & & CA III & CA II \\
\hline Periportal hepatocytes & $55 \pm 9$ & $69 \pm 9$ & & $52 \pm 18$ & $33 \pm 10$ \\
Perivenous hepatocytes & $84 \pm 21$ & $325 \pm 97$ & & $113 \pm 34$ & $167 \pm 34$ \\
Significance & $P<0.05$ & $P<0.05$ & & $P<0.05$ & $P<0.05$ \\
PP:PV & $1: 1.5$ & $1: 5$ & & $1: 2$ & $1: 5$ \\
\hline
\end{tabular}

Values are means $\pm \mathrm{SE}$ in $\mu \mathrm{mol}$ converted $\mathrm{CO}_{2} \cdot \mathrm{min}^{-1} \cdot \mathrm{mg}_{\mathrm{p}}$ )rotein ${ }^{-1}$ Student's paired $t$ test analysis determined that perivenous carbonic anhydrase activities were higher than periportal activities even after values had been corrected for protein concentrations.

CA being found there, it was always assumed that the staining was in some way artifactual (31). This report presents the first evidence for nuclear-associated CA and opens the way for a rigorous study of its physiological function.

There have been previously contradictory immunohis tochemical reports about the distribution of CA III in the liver: first, that CA III is located exclusively in the perivenous cytosol (5) and, second, that CA III is homogeneously distributed throughout the perivenous and periportal cytosols (23). This present report demonstrates vividly the limitations of immunohistochemical techniques in determining physiological functions for enzymes with isozymes of widely differing turnover numbers. The histochemical technique used to obtain this picture, the Ridderstrable technique, relies solely on the activity of CA and not on its protein concentration. CA II is known to have a turnover number that is, arguably, the highest of any mammalian enzyme. All previous histochemical studies of rat liver CA isozymes have used immunohistochemical methods with antibodies that demonstrate the presence of the various isozymes but not their relative contributions to total CA activity. We have recently reported a membrane-bound CA associated with the rat liver endoplasmic reticulum (26). The endoplasmic reticular $\mathrm{CA}$ activity is included in the membrane fraction and is labeled CA IV in Table 3.

The data in this report indicate there is little or no functional CA I activity in the cytosolic or homogenate samples. This is the first time that the functional absence of this enzyme has been reported. Although immunohistochemical evidence for CA I has been reported from one laboratory (23), another laboratory has consistently reported its inability to detect CA I by immunohistochemical studies $(5,19)$ or by other means $(4)$.

Because CA IV is membrane bound (14) and CA V is exclusively mitochondrial (6-8), we conclude that only CA II and CA III contribute to the CA activity of either periportal or perivenous cytosolic eluates. We discount the possibility that $\mathrm{CA} V \mathrm{~V}$ can leak out of mitochondria and contribute to eluate CA activity. First, CA V activity provides $<5 \%$ of the total CA activity in liver homogenates (7), so even if all the mitochondria were disrupted, CA V would still contribute little to total CA activity.

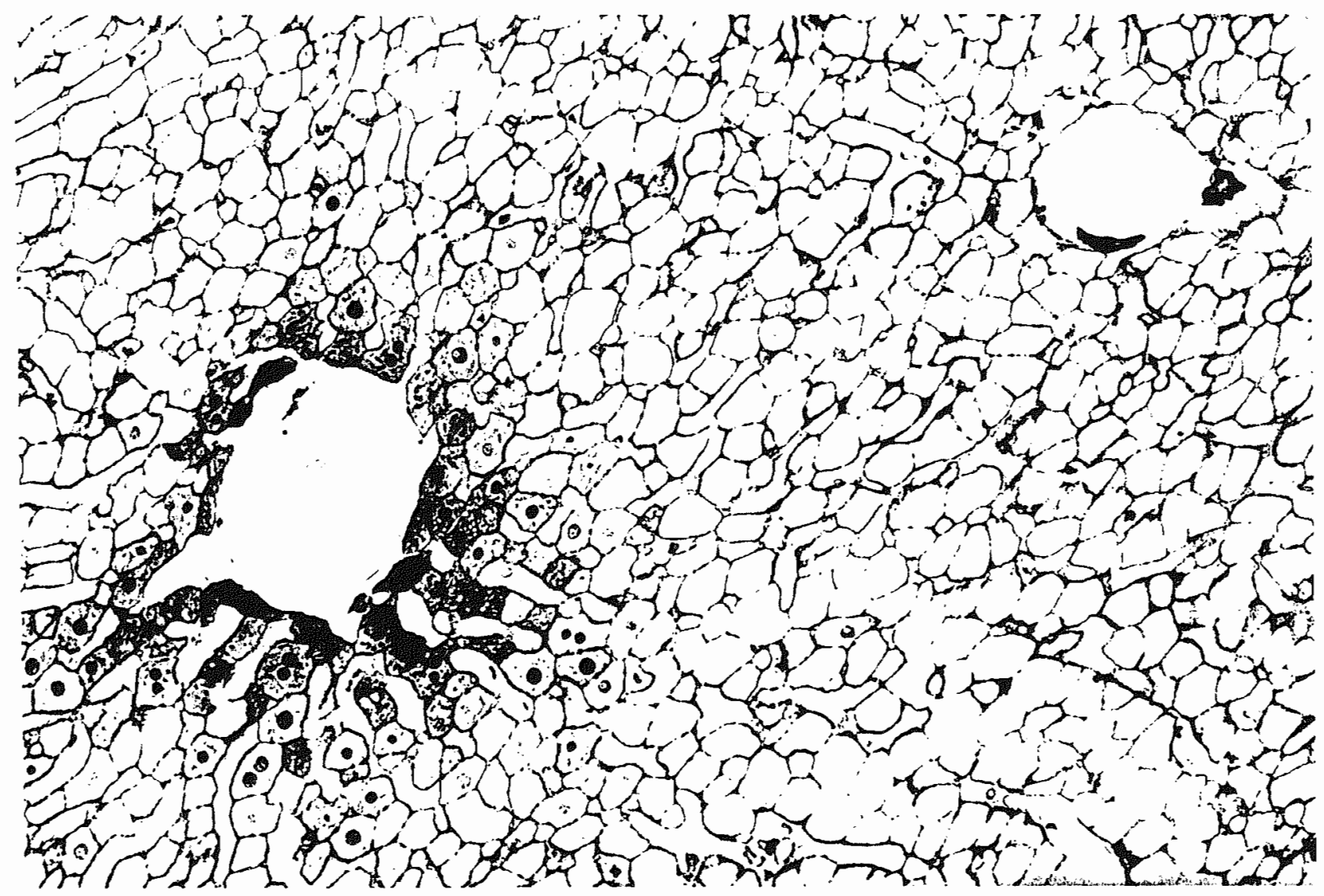

F1G. 3. Fed rat liver, $\times 300$. All hepatocytes show intense staining at cell membranes. Strong nuclear and cytoplasmic staining in perivenous hepatocytes (left) and in bile ducts (top right). 


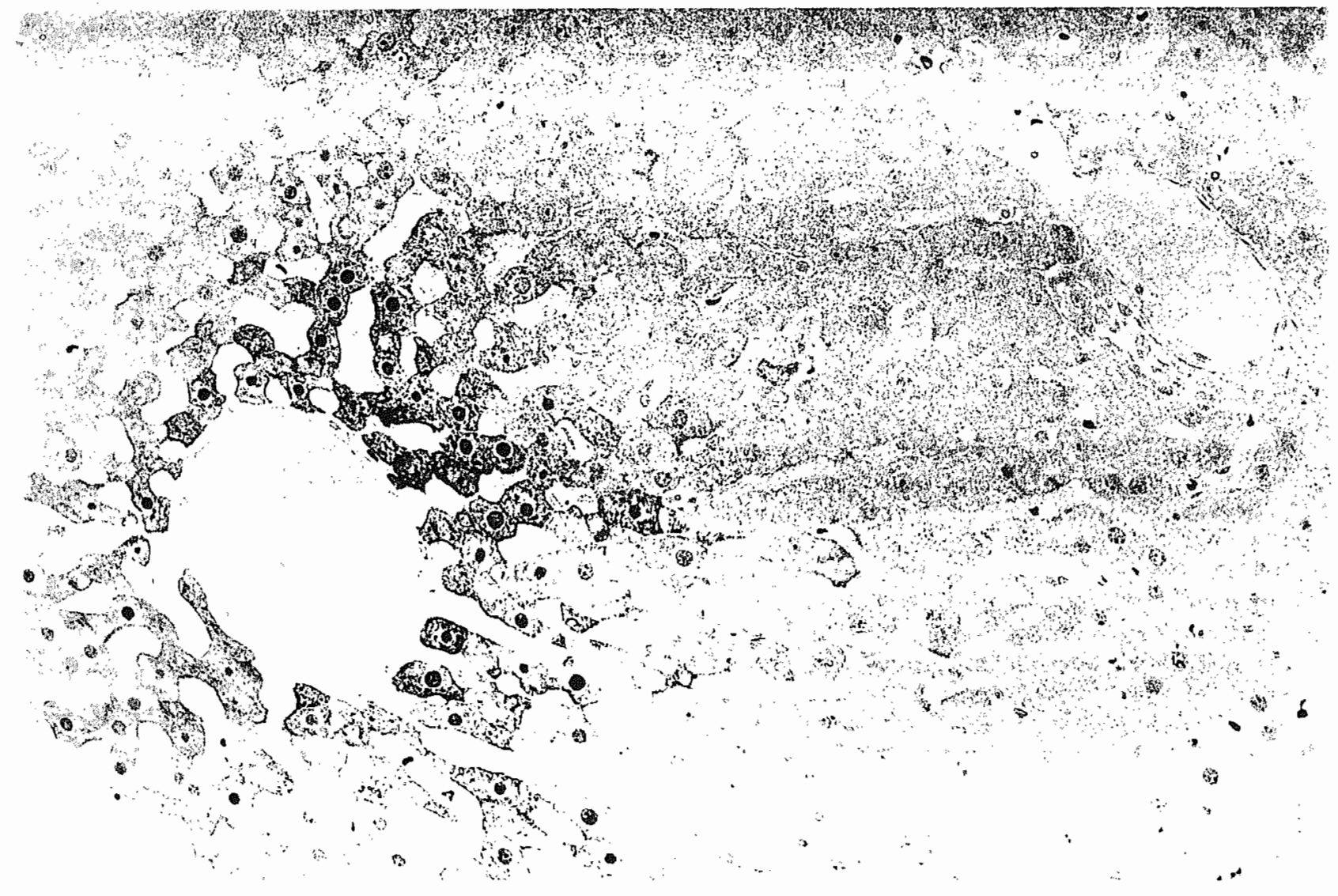

FIG. 4. Carbonic anhydrase activity in presence of $1 \mu \mathrm{M}$ acetazolamide in fed rat liver, $\times 300$. Lightly stained perivenous hepatocytes (left); darkest stains represent nuclei. In contrast with Fig. 3, there is no carbonic anhydrase activity on membranes.

Second, the mitochondria were not disrupted, as can be seen from the lack of glutamate dehydrogenase activity in the cytosols. Thus, even if CA V had leaked out when glutamate dehydrogenase did not, it would have contributed little to the overall CA activity. The elution of the mitochondrial marker enzyme glutamate dehydrogenase was $<0.2 \%$ of the activity in the homogenate, indicating that little mitochondrial protein was released.

The data in Table 2 confirm that the digitonin-pulse technique elutes cytosolic samples separately from the perivenous and periportal regions of the liver, since the cytosolic marker enzymes that are known to be localized to one or the other region, glutamine synthase and alanine amino transferase, have differing activities in the perivenous and periportal cytosols.

The data in Table 1 indicate that in starved rat livers the cytosolic isozymes decrease but the membranebound CA IV does not. It has been previously reported that rat $\mathrm{CA} V$ activity (in $\mathrm{mg}$ mitochondrial protein ${ }^{-1}$ ) is unaltered by $48 \mathrm{~h}$ of starvation (7) and thus that CA V activity in both fed and starved rat livers is calculated to be $<5 \%$ of total CA activity. The considerably greater contribution of CA IV activity to total CA activity is also indicated in the histochemical pictures. This is the first report of homogeneous distribution of CA IV in the liver.

Regulation of rat liver CA isozymes by steroid hormones and the peculiar sexual dimorphism of CA II and CA III, attributed to the effects of testosterone on the episodic release of growth hormone, have been investi- gated previously $(4,19)$. It has been reported that maximal concentrations of CA III in male rats are attained at puberty, after which the concentrations decrease until senescence, at which time CA III concentrations in males and females are indistinguishable (4). It is likely that the altered activities of the cytosolic CA isozymes found in rats starved for $48 \mathrm{~h}$ also result from changes in steroid hormone release.

We thank L. Lin and M. Eng for preparing $\mathrm{NaHC}^{18} \mathrm{O}^{16} \mathrm{O}$ and maintaining the mass spectrometer.

The mass spectrometer facility was supported by National Institutes of Health Grant HL-PO19737 (program director R. E. Forster II). This research was supported by National Institutes of Health Grants HL-47815 (R. E. Forster II) and DK-38041 (S. J. Dodgson), Danish Research Council Grant 5.17.14.5 (B. Quistorff), and Swedish Council for Forestry and Agricultural Research Grant SJFRD-290 (Y. Ridderstråle).

Address for reprint requests: S. J. Dodgson, Dept. of Physiology, Univ. of Pennsylvania School of Medicine, Philadelphia, PA 191046085 .

Received 19 May 1992; accepted in final form 5 March 1993.

\section{REFERENCES}

1. Bergmeyer, H. U. Methods in Enzymatic Analysis. Weinham, Germany: Verlag Chenie, 1974

2. Bols-Joyeux, B, M. Chanez, F. Aranda-Haro, and J. Peret. Age-dependent hepatic lipogenic enzyme activities in starved-refed rats. Diabete Metab. 16: 290-295, 1990.

3. Carter, N. D., S. J. Dodgson, And P. A. Quant. Expression of hepatic mitochondrial carbonic anhydrase V. Biochim. Biophys. Acta 1036: 237-241, 1991. 
4. Carter, N. D., A. Shiels, S. JefFery, R. Heath, C. A. Wilson, I. R. Phillips, AND E. A. Shephard. Hormonal control of carbonic anhydrase III. Ann. NY Acad. Sci. 429: 287-301, 1984.

5. Carter, N. D., P. J. Wistrand, and G. Lönnerholm. Carbonic anhydrase localization in perivenous hepatocytes. Acta Physiol. Scand. 135: 163-167, 1989.

6. DoDGSON, S. J. Why are there carbonic anhydrases in the liver? Biochem. Cell. Biol. 69: 761-763, 1991.

7. Dodgson, S. J., AND L. C. Contino. Rat kidney mitochondrial carbonic anhydrase. Arch. Biochem. Biophys. 260: 334-341, 1987.

8. Dodgson, S. J., R. E. Forster II, B. T. Storey, AND L. Mela. Mitochondrial carbonic anhydrase. Proc. Natl. Acad. Sci. USA 77: 5562-5566, 1980.

9. Dodgson, S. J., G. Gros, J. A. Krawiec, L. Lin, N. Bitterman, AND R. E. FORSTER. Comparison of ${ }^{18} \mathrm{O}$ exchange and $\mathrm{pH}$ stop-flow assays for carbonic anhydrase. J. Appl. Physiol. 68: 2443-2450, 1990 .

10. DoDGson, S. J., AND M. WATFORD. Carbonic anhydrase activity in livers from streptozotocin-diabetic rats. Arch. Biochem. Biophys. 277: $410-414,1990$

11. EVANS, J, L., B. QUISTORFF, AND L. A. WITTERS. Zonation of hepatic lipogenic enzymes identified by dual-digitonin-pulse perfu. sion. Biochem. J. 259: 821-829, 1989.

12. Evans, J. L., B. QUISTORFF, AND L. A. WITTERS. Hepatic zonation of acetyl-CoA carboxylase activity. Biochem. J. 270: 665-672, 1990

13. FORSTER, R. E., Il. Methods for the measurement of carbonic anhydrase activity. In: The Carbonic Anhydrases: Cellular Physiology and Molecular Genetics, edited by S. J. Dodgson, R. E. Tashian, G. Gros, and N. D. Carter. New York: Plenum, 1991, p. 79-98.

14. Garcla-Marin, J. J., F. Perez-Barriocanal, A. Garcia, M. A SERrano, P. REgUEIRo, AND A. Esteller. Evidence for the presence of carbonic anhydrase in the plasma membrane of rat hepatocytes. Biochim. Biophys. Acta 945: 17-22, 1988.

15. GEBHARDT, R., AND D. MECKE. Heterogeneous distribution of glutamine synthetase among rat liver parenchymal cells in situ and in primary culture. EMBO J. 2: 567-570, 1983

16. GUDER, W. G., AND U. SCHMIDT. Heterogeneity of enzyme activities in the rat liver. Hoppe-Seyler's Z. Physiol. Chem. 357: 1793$1800,1976$.

17. GUZMAN, M., AND J. CASTRo. Zonation of fatty acid metabolism in rat liver. Biochem. J. 264: 107-113, 1989.

18. ITADA, N., AND R. E. ForSTER II. Carbonic anhydrase activity in intact red blood cells measured with ${ }^{18} \mathrm{O}$ exchange. $J$. Biol. Chem. 252: 3881-3890, 1977.

19. JEFFERY, S. Hormonal regulation and localization of rat liver car bonic anhydrase. In: The Carbonic Anhydrases: Cellular Physiology and Molecular Genetics, edited by S. J. Dodgson, R. E. Tashian, G. Gros, and N. D. Carter. New York: Plenum, 1991, p. 289-295.
20. JiLKa, R. L., J. L. Rogers, R. G. KHALIFAH, AND H. K. VÄÄNÄNEN. Carbonic anhydrase isozymes of osteoclasts and erythrocytes of osteopetrotic microphthalmic mice. Bone 6: 445-449, 1985.

21. KorchaK, H. M., AND E. J. MASORo. Changes in the level of fatty acid synthesizing enzymes during starvation. Biochim. Biophys. Acta 58: 356-358, 1962

22. KReBS, H. A., AND K. Henseleit. Untersuchungen uber die Harnstoffbildung in Tierkoper. Hoppe Seyler's Z. Physiol. Chem. 210: $33-66,1932$

23. Laurila, A. L., E.-K. Parvinenen, J. W. Slot, and H. K VÄANÄANEN. Consecutive expression of CA isoenzymes during development of rat liver and skeletal muscle differentiation. $J$. Histochem. Cytochem. 37, 1375-1382, 1989.

24. Lowry, O. H., N. J. Rosebrough, A. L. FARR, AND R. J. RANDALL. Protein measurement with the Folin phenol reagent. J. Biol. Chem. 193: 265-275, 1951 .

25. MoIR, A. M., AND V. A. Zammit. Changes in the properties of cytosolic acetyl-CoA carboxylase studied in cold-clamped liver samples from fed, starved and starved-refed rats. Biochem. J. 272: 511-517, 1990.

26. ONO, Y., Y. Ridderstråle, R. E. Forster II, Z.-G. ChU, AND S. J. DodGSON. Endoplasmic reticular carbonic anhydrase. Proc. Natl. Acad. Sci. USA. 89: 11721-11725, 1992.

27. QuISTORFF, B. Metabolic heterogeneity in liver parenchymal cells. Essays Biochem. 25: 83-136, 1990.

28. QuistorfF, B., AND N. GRUNNET. Dual-digitonin-pulse perfusion. Concurrent sampling of periportal and perivenous cytosol of rat liver for determination of metabolites and enzyme activities. Biochem. J. 243: 87-95, 1987.

29. QUistorfF, B., N. GRUNNET, AND N. W. Cornell. Digitonin perfusion of rat liver. A new approach in the study of intra-acinar and intra-cellular compartmentation in the liver. Biochem. $J$. 226: 289$297,1985$.

30. QUISTORFF, B., AND P. RøMERT. High zone-selectivity of cell permeabilization following digitonin-pulse perfusion of rat liver. A reinterpretation of the micro-circulating zones. Histochemistry 92 487-498, 1989

31. RIDDERSTRÅLE, Y. Localization of carbonic anhydrase by chemical reactions. In: The Carbonic Anhydrases: Cellular Physiology and Molecular Genetics, edited by S. J. Dodgson, R. E. Tashian, G. Gros, and N. D. Carter. New York: Plenum, 1991, p. 133-144.

32. SASSE, D., N. B. KATZ, AND K. JUNGERMANN. Functional heterogeneity of rat liver parenchyma and of isolated hepatocytes. FEBS Lett. 57: 83-88, 1975 .

33. Spydevold, S. O., AND A. L. GreenBaum. Adaptive responses of enzymes of carbohydrate and lipid metabolism to dietary alter ation in genetically obese Zucker rats $(\mathrm{fa} / \mathrm{fa})$. Eur. J. Biochem. 89 $329-339,1978$. 